\title{
Perceptions of beneficiaries and health
}

professionals regarding a conditional cash transfer program to improve pregnancy follow-up: a

qualitative analysis of the NAITRE randomized controlled study

\section{AURELIE GODARD MARCEAU ( $\square$ amarceau@chu-besancon.fr )}

Centre Hospitalier Universitaire de Besancon https://orcid.org/0000-0002-1019-8300

Nicolas Meunier-Beillard

Centre Hospitalier Universitaire de Dijon

Philippe Deruelle

Hopitaux universitaires de Strasbourg

Mathieu Morin

centre hospitalier universitaire de Toulouse

Claude Virtos

centre hospitalier de Dreux

Astrid Echman-Lacroix

Centre Hospitalier Universitaire de Besancon

Elodie Debras

Assistance Publique - Hopitaux de Paris

Laurent Laforet

Centre Hospitalier Universitaire de Dijon

Marc Bardou

Centre Hospitalier Universitaire de Dijon

Research article

Keywords: Pregnancies, Low-Income Populations, CCT program, Qualitative Research, Ethics

Posted Date: March 10th, 2020

DOI: https://doi.org/10.21203/rs.3.rs-16575/v1

License: (c) (i) This work is licensed under a Creative Commons Attribution 4.0 International License.

Read Full License 


\section{Abstract}

Background: Economic incentives have been used in several countries to improve pregnancy follow-up, to encourage families to bring their infants to see a doctor, and to promote school attendance. However, these conditional cash transfer programs (CCTs) are often subject to criticism. The NAITRE study, which is currently underway in France, assesses the use of CCT to promote prenatal care in women with low socioeconomic backgrounds and has also been the focus of such criticism. The objective of the qualitative study was to analyse how the CCT is perceived by the women and health professionals involved in the project. These data are essential for in-depth understanding of the elements that could encourage or deter a generalization of the process. Methods: A multicentre, cross-sectional, qualitative study was conducted among 26 women included in the NAITRE trial and 8 health professionals (physicians and midwives). All data were collected through semi-structured individual interviews and transcribed in their entirety. A thematic content analysis was then used to generate the results. Results: In the interviews, the women expressed surprise regarding the offer of a cash incentive. However, they did not perceive the CCT negatively, but saw it rather as a significant source of aid for women with limited financial resources. Some even expressed feeling as though they were supported far beyond the financial support. The health professionals were much less positive. Still, though they all stressed the ethical considerations related to the premise of the trial, they recognized the need for such an evaluation. Conclusions: In a country where access to health care is facilitated by a nationalized health insurance system, the use of a CCT to improve medical follow-up during pregnancy raises ethical questions for the health professionals involved. However, an analysis of the interviews conducted with the women who received compensation showed that they did not feel stigmatized. While the women generally reported that the CCT money allowed them to better prepare for the birth, none indicated that they changed their behaviour relative to medical follow-up during the pregnancy.

\section{Background}

Various analyses have shown that women in precarious living situations attend fewer medical appointments during pregnancy, either for financial reasons (1) or because they are faced with a combination of economic and social difficulties that make it challenging to organize care $(2,3)$. It has been shown that suboptimal pregnancy follow-up, defined as less than $80 \%$ or less than $50 \%$ of scheduled follow-up, is associated with a two-fold risk of severe maternal and neonatal morbidity $(4,5)$. Several countries, mostly of low or medium income, have introduced economic incentives, hoping (among other things) to encourage women to consult during pregnancy $(4,6)$ or to encourage families to have their young children followed by a doctor or sent to school (7). For the most part, this type of cash incentive program has been implemented in developing countries, particularly in Latin America with the Bolsa Familia Program in Brazil (7), Solidario in Chile (7) or the PROGRESA-Oportunidades program in Mexico (8.9). Though less common, studies of this nature have been conducted in Europe as well, usually targeting specific illnesses such as mental illnesses (10) or behaviours such as smoking during pregnancy $(12,13)$. 
Evaluative studies have shown the beneficial effects of these programs, though the results must be placed in context $(5,8-11,13)$. In reality, few of these studies were randomized controlled trials - the majority analysed the effects of the programs before and after, which does not take into account changes between the two periods. A systematic review published in 2015 concluded on a need for high-quality randomized controlled trials (RCTs) to determine whether incentive programs increase prenatal care use and improve maternal and neonatal outcomes (15).

In addition, conditional cash transfer (CCT) programs have been criticized on a number of points: paternalism, clientelism, and administrative burdens to name a few (16). The NAITRE study, currently conducted by our team, (17) (NCT02402855) has been subject to the same types of criticism from health professionals and from members of our ethics committee. Two main issues were raised: i) the risk that the women would be stigmatized and ii) the fear that the introduction of an economic incentive could alter the relationship between the pregnant women and their health professionals, which is based on mutual trust.

In France, the national health insurance system covers almost all pregnancy-related health costs (consultations, biological and ultrasound examinations), so offering an economic incentive to women of low socio-economic background has raised ethical questions. In order to address the concerns raised by the NAITRE study, a qualitative study aimed at understanding how women perceive and experience the proposed incentive was conducted at the beginning of the inclusions. It was decided that the preliminary results of this qualitative analysis were to be reviewed by the data monitoring and safety committee (DSMC) after the first year of recruitment, and that the inclusions would only continue beyond the first year if it was established that the CCTs were not negatively perceived by the women. In addition to this first phase, we analysed discussions with the health professionals who had agreed or refused to participate in the project.

The objective of this article is therefore to analyse how the various participants viewed the CCT project.

\section{Methods}

\section{Design of the study}

The NAITRE study evaluates a CCT for adherence to scheduled prenatal follow-up, and the effect on the occurrence of maternal or neonatal complications. NAITRE is a pragmatic multi-centre, open-label clusterrandomized trial using a parallel arm design, in which women receive (intervention group) or not (control group) a $30 €$ incentive for attending each scheduled prenatal consultation, with a maximum of one compensated consultation per month.

Prenatal follow-up is left to the discretion of the appropriate health professionals in compliance with the current French recommendations and the practices of each centre. 
We conducted a multi-centre, semi-managed, face-to-face, cross-sectional, qualitative study in order to analyse the perceptions of the women and health professionals involved. The interviews were conducted with i) the women included in the NAITRE trial, in both arms of the study: the control arm (i.e. standard management of pregnancy follow-up) and the intervention arm (i.e. CCT for pregnancy follow-up) and ii) health professionals (obstetricians and midwives) who either agreed to participate in the NAITRE trial or refused the implementation of the NAITRE trial in their centre.

\section{Participants and sample selection}

Eligibility criteria for the NAITRE trial were as follows: (1) pregnant woman, (2) aged 18 or older, (3) who attended their first pregnancy consultation in one of the participating centres before the end of the 26th week of amenorrhea, and (4) with health insurance for low-income families (Universal Medical Coverage or Couverture Médicale Universelle, $\mathrm{CMU}$ ) or illegal immigrant status (State Medical Coverage or Aide Médicale d'Etat, AME). The only two exclusion criteria were: (1) women not able to understand the study and (2) women under judicial supervision.

For the qualitative study, women were selected 3-6 months after delivery depending on their medical follow-up during pregnancy. Every woman included in the NAITRE study was eligible for the qualitative study except in case of stillbirth, post-natal death or if the baby was diagnosed with a severe medical condition. In these situations, it would have been delicate to collect accurate information about the pregnancy or even to approach them for the study.

This qualitative study also focused initially on a geographical selection of women included in the NAITRE to take into account different type of precariousness encountered (rural, urban, former industrial area, or illegal immigration area). The inclusion sites were then expanded to allow the inclusion of patients with specific characteristics (non-compliant or primiparous).

To ensure adequate maximal variation sampling, women were selected after delivery in both the intervention and control groups to obtain different ages, primiparous and multiparous status, different economic conditions and different adherence to prenatal care.

Semi-structured individual interviews aimed to understand the determinants of medical follow-up during pregnancy. The principle was to get the respondents to describe situations that highlight their habits, their social representations or their emotions. Women were asked to describe their health practices during pregnancy, what was important for their medical follow-up and what led them to adhere or not to scheduled prenatal care. Women who received the CCT were also asked how they felt about the incentive and what it may or may not have brought them.

Participants were approached by phone (women) ou email (professionals). Women were interviewed at the hospital where they had been followed-up during pregnancy or at their home, and some interviews were conducted by telephone. The women who took part in the interviews received a $40 €$ compensation for their time, irrespective of the group they belonged to during their pregnancy follow-up. 
For health professionals, the eligibility criteria for the qualitative study were as follows: (1) obstetrician or midwives whose centre or unit had been contacted for the NAITRE study, irrespective of participation (17) (2), and who agreed to participate in a personal qualitative interview. There were no exclusion criteria. The study population was divided into three sub-populations: i) physicians/midwives who agreed to participate in the study and who included patients, ii) physicians/midwives who agreed to participate in the study but who included few or no patients, iii) physicians/midwives who declined to participate in the study.

The semi-structured interviews were designed to get the health professionals to describe the factors that led them to participate in the NAITRE study or not. An additional aim was to understand the potential assets or obstacles for scaling up the CCT as standard practice if the NAITRE program showed a real impact on reducing pregnancy complications in the target population, likely as a result of improved prenatal care.

\section{Ethics}

Ethics approval from CPP EST-I was first gained on September 28th 2014. An independent data security and monitoring committee has been established.

\section{Data collection}

Data were collected by two health sociology researchers working in a clinical center research (INSERM/CHU) (1 female PhD - AGM- and 1 male Master-NMB) with expertise in conducting qualitative interviews, over a 38-month period from May 2017 to July 2019. Two specific individual and semistructured interview guides (for the women and the health professionals) were developed jointly with social science researchers and the clinicians leading the research. These guides were the subject of preliminary test interviews in order to ensure that the topics were clearly understood and that they matched to the issues established by the research team, and any necessary changes were made. The final version of the guides is available in the appendix.

All interviews were recorded and transcribed in their entirety, as well as the notes taken in the field (in particular the presence of the husband during the interview and the influence of their presence on the interview).

\section{Data analysis}

Raw data were analysed according to a thematic analysis method. Two sociologists coded the interview transcriptions to obtain data triangulation. Qualitative data was analysed during and after the data collection.

Data collection continued until theoretical saturation was reached, meaning that no new data would have added additional information to the concepts outlined in the research objectives. 
An inductive approach was used to identify patterns and themes, and thematic data analysis was conducted. Transcripts were examined thoroughly by the authors, and the topics that repeatedly emerged were highlighted and categorised as themes. These themes were reviewed and discussed between coauthors to avoid personal bias and to ensure analytic robustness. This was followed by further verification and validation of the themes with the available literature for the purpose of triangulation. The final themes were then summarized according to the pattern of findings.

\section{Results}

\section{Inclusion results}

Of the 3500 women included in the qualitative branch of the NAITRE study (February 2017-June 2019), 60 women were contacted: 6 refused outright, 9 did not attend the appointment and 19 women never responded to our calls. Finally, 26 women were interviewed. The majority of interviews were conducted at the counselling centre $(\mathrm{N}=16)$, and the rest were conducted at the woman's home $(\mathrm{N}=6)$ or by telephone $(\mathrm{N}=4)$. An interpreter was required for five interviews: a professional interpreter was present during 3 interviews and the husband translated for the remaining two. Overall, five husbands were present during the interviews. The interviews lasted an average of 28 minutes.

The inclusions initially focused on women recruited at Besançon University Hospital, Lille University Hospital and Bicêtre Hospital in the Paris suburbs. These centres were chosen because they represent certain types of French cities and precarious situations: a city with a close rural population (Besançon), an old industrial city (Lille), and a metropolis with a large migrant population (Robert Debré Hospital in the Paris conurbation). However, because of the difficulties in including non-adherent patients, inclusions were extended to all participating centres (Table 1).

Seventeen non-adherent women (who missed at least two appointments) were contacted, but only three were included in the study. Two refused to participate in the study, and we were not able to contact the others (phone numbers that were no longer in service, answering machines).

Characteristics of the included women are depicted in Table 2.

At the start of the qualitative study, 51 centres (university hospitals, local hospitals or care centres) were contacted to join the NAITRE study; 35 finally participated. We contacted 15 centres to request interviews with health professionals, and a total of four physicians and four midwives agreed to participate in qualitative one-on-one interviews. Only one interview was conducted with a health professional from a centre that refused to participate in the study. For reasons of confidentiality, we will not specify the centres involved. The interviews lasted an average of 20 minutes.

\section{Women's perception of the CCT initiative}

Of the 26 women interviewed, 14 had received a cash incentive. These women described feeling surprised when it was offered to them. The CCT approach was seen as uncommon, and as unusual for the French 
health system.

Patient: At first, I thought it was weird, because I thought to myself why are they giving me money because I'm pregnant, I don't know..., I found it a little... I'd never seen it so I didn't know how to take it actually. On the one hand, I'm happy because it's not... how do you say, it's nice to have $30 €$ to buy something, but on the other hand I didn't understand, I thought why? But hey. (FB1)

Yet this astonishment was not experienced negatively, and, for these women with limited resources, the CCT was seen as positively.

Interviewer: What did you think of this proposal when the doctor told you about it?

Patient: Well, I thought it was good. Because I've never had a credit card before, that was good. I buy, I feel like I have a card to buy what I want from time to time, it wasn't huge but it was good. (FB2)

Women decided how to spend the compensation. They described using it to pay for transportation to the hospital when it was complicated, to supplement the family budget and most often to buy the baby's essentials. The women spoke of this financial compensation as a contribution to the well-being of the family. Considering their precarious situation, they were pleased to receive the money.

Patient: And I thought it was interesting and one day I came home and said to my husband, "Yes, frankly that's a good system they set up because I realize that there are people, it's true that financially they can't and it's really a plus", because when you're pregnant you really want to eat special things and I realize that it helps to feel good during pregnancy and I honestly thought it was great. FP(13)

When I knew she was a girl, when I was sure [laughing], then I started buying things for her. Like the things you need in the hospital, for example, the first pack of diapers, wipes, cotton, things like that. (FB1)

Three women indicated that they had saved up in order to buy more costly equipment for the baby (for example change table or baby gate).

Women who did not receive financial compensation during the study were presented with a theoretical situation: "What would you think if women were offered economic compensation every time they consulted during their pregnancy?". The women initially expressed surprise, and several indicated that they would have refused such a proposal.

Patient: Uh, no, that's a bad idea.

Interviewer: Yes?

Patient: I don't think that's such a good idea, actually.

Interviewer: What bothers you about it?

Patient: To pay a person to go for the consultation. 
Interviewer: Yes?

Patient: But wait, it's her baby, it's her baby plus it's herself, it's her health and the health of the baby you're carrying. (FP4)

It should be noted, however, that only one woman refused financial compensation for the qualitative interview, a refusal initiated by her husband.

Yet almost all of them pointed out that a cash incentive could be a significant help for low-income women in precarious living conditions, and in particular to help them prepare for their babies.

I told one of my friends about it "and you know that now they do programs and such for people who have the RSA or CMU, they give $30 €$, honestly it's so good and everything " because I know I have friends they didn't eat during their pregnancy, it was tough sometimes. FP(13)

Whether in the control or intervention group, women had difficulty estimating the financial compensation that would successfully encourage women to attend consultations. They indicated that the needs depend on the family situation. They also pointed out that whatever amount is offered is beneficial for the family and is therefore positive.

During the interviews, there were two straightforward objections to this compensation which came from the husbands present at the interview and not from the women. The first one, (intervention group) refused to let his wife use the money for fear that the medical staff could then claim rights over the unborn children (FP8); the second (control group) refused the compensation offered the end of the interview, indicating that he had come to provide us with information but did not need the money (FP1).

Whether or not they received financial compensation during the study, the women claimed that a CCT would not have changed their behaviour because they say they would have consulted anyway. Only one woman indicated that she could have done without medical follow-up during her pregnancy (FT2). On the whole, the women we met recognized the importance of medical follow-up either because they had already had health concerns during previous pregnancies (8), or because they were aware of the importance of follow-up for both mother and child.

Patients: With the examinations, the follow-up, they detected, they gave me the necessary check-up and I had no problems apart from the diagnosis of pregnancy at 28 weeks it was very good again, because back home, in A[Country], I didn't do a screening for gestational diabetes and I even think, maybe I had gestational diabetes there that I didn't know, because the girl was born at $3.8 \mathrm{~kg}$. Maybe I developed gestational diabetes that I didn't even know I had. FP(22)

None of the women reported that receiving a cash incentive changed their habits regarding medical consultations.

Health professionals' perception of the CCT initiative 
Health professionals who agreed to participate in the study and those who did not perceived the economic compensation differently. The CCT itself was the most frequent reason for declining to participate in NAITRE. We identified two arguments against compensation. First, the very notion of a CCT program poses an ethical problem to opponents of this study. In a hospital system where health professionals never talk about money with users, having to address a monetary aspect and then validating the payment of compensation was a problem, even if the money was wired to the women's payment cards directly by the coordinating centre of the NAITRE study.

Caregiver: I told myself that... not to mix up the medical follow-up, we'll say and then the financial aspect of things. I don't know, there was something in that that that shocked me. For me, you have to separate the two, and the fact that in the end the medical staff validates the fact that that there is behind a financial side, frankly for me they mixed the genres and that's it. (PN1)

Second, health professionals are concerned that women in the control group may be informed that other women are receiving money. This situation has already happened in certain departments:

What also happened is that we have patients who know each other, who come from the same neighbourhood or the same area, and I have already had patients who said "but I don't understand, a friend of mine received money, I have nothing, what's going on?" So twice, it's not that big a deal, but there were two, so when this patient told me about it, I kind of avoided the question and said "but the study is ending", well, I don't know what I said anymore to try to...(PB2)

For the professionals who accepted the study, offering economic compensation also raises questions from an ethical point of view, but this was not an obstacle to their participation. The principle is that the study must make it possible to verify the impact of the CCT program, and the teams emphasized their desire to participate in research.

At the time, we were just starting to set up studies in the department, because we didn't have a lot of clinical research until then, we had one or two studies in progress. And then, well, as we had practitioners that were really dedicated to obstetrics we were able to set up a little more, so we were motivated to do, to help with clinical studies. It's not that anymore. (BM)

However, from a practical point of view, they do not see how this type of CCT could be generalized given the increasing lack of hospital funding.

For everyone we interviewed, the CCT program is not the key to getting reluctant women to adhere to pregnancy follow-up. Rather, they suggest the importance of early follow-up, regular calls and comprehensive individualized care.

We have set up specific consultations, over a period longer than one hour, where we try to build trust and work in a multidisciplinary way, i.e. in conjunction with social workers, the PMI [Protection Maternelle et Infantile], charities if necessary, and so on. And generally, setting up these consultations finally helps to 
build patients' trust and to see them more regularly and in a way..., well, they come. They come for the consultation. (BSF)

\section{Data limitations}

The sample of women interviewed does not sufficiently represent non-adherent women. Understandably, it was more complicated to contact them, either because they did not take our calls or because they did not have a phone.

In addition, since the qualitative study was conducted primarily in university hospitals, many of the women included had a medical history, which had an impact on their vision of medical follow-up during pregnancy.

The study's inclusion criteria excluded women whose first consultation took place after 26 weeks of amenorrhea. Thus, women who came to give birth without any follow-up during their pregnancy were not interviewed for this study.

Included women had access to the $\mathrm{CMU}$, which was a specific social security system dedicated to those most in economic difficulty. To access the CMU, it is necessary to carry out administrative procedures that are often long and laborious. Thus, women who were socially "off the grid" were not included in this study.

The study of health professionals was developed two years after the beginning of inclusions. At this point, many of the physicians who had refused the study had changed departments and were not reachable.

\section{Discussion}

The results of this study show that while women expressed mostly very positive feeling about the CCT program, health professionals are reluctant overall. Those who are clearly opposed to it believe that it poses an ethical dilemma, while others consider that it is not the best way to get women to adhere to medical follow-up during pregnancy.

\section{A perception that depends on one's experience}

The cross-referenced analysis of the interviews with the health professionals and women showed that each individual had a very different perception of the CCT. Health professionals who were not opposed to the CCT considered that, though it was worth testing, it did not seem to be a miracle solution. For the women participating in the study, the cash incentive was seen differently depending on whether or not they received it. The women who were part of the CCT program viewed it positively, mainly because the money was useful for personal or child-related expenses. CCT programs have improved the well-being of families in all countries where they have been implemented. Children and women are the first beneficiaries of theses cash transfers $(6,18,19)$. According to the patients, the cash incentive did not go to 
the husbands, which corroborates anthropologists' data that show that the incomes of women in precarious situations (whether in developing countries or not) are mainly used for daily child-related expenses $(20,21)$. In short, the money is seen as more as aid than an incentive. For those who were not compensated by the CCT program, the idea of receiving money to attend their consultations seemed surprising and even out of purpose, at least initially.

None of the women interviewed indicated that the cash incentive changed their behaviour, although from what was said, it appears that this could change the outlook of someone who did not understand the value of the consultations. While adherent women tend to see consulting as normal behaviour (22), nonadherent women indicate that as long as they are feeling well, they do not see the benefit of going to the hospital. For women who have limited medical knowledge, their feelings and emotions result in nonadherence (23).

For health professionals, the CCT program was generally negatively perceived. Six of the eight professionals interviewed here worked in hospitals. In France, physicians or midwifes practicing in a public hospital have no financial relationship with patients. Low incomes are rarely to blame for a lack of access to care in hospitals because of the French national health insurance system, but economicallymotivated limits are often cited by physicians in private practice (24). In the current context of cost savings imposed on French public hospitals, the idea of offering patients a sum of money is seen as a misallocation of resources that would be more useful if they were used to improve the care offer. In addition, professionals felt that there was an ethical problem associated with the NAITRE randomised clinical trial because it disregards the principle of equality (some participants had compensation, others did not). This concern is of interest because it may reflect the expression of a hidden fear, as it is the basis of randomization in clinical trials to break the principle of equality. Some interviewees described situations where patients complained that other patients were receiving money, causing tension in the relationship between the caregiver and the patient. Given that comparing two populations with different interventions is the principle of clinical research, this criticism seems more related to the use of randomized control trials in economics (25). When it comes to medication, this type of trial is acceptable because it is the most reliable way to analyse their effects. However, taking the same approach with social and economic behaviour is harder to accept for some professionals. Their criticism is in line with those of others who have studied economics on the subject $(26,27)$ and is perhaps a result of the loss of "equipoise". The concept of equipoise, which is the central ethical principle of randomized control trials, holds that a subject may be enrolled only if there is true uncertainty about which of the trial arms is most likely to be beneficial (28).

Our group of health professionals all said that they though the CCT program would stigmatize vulnerable individuals, a reproach which has been expressed in previous literature (29). However, none of the woman expressed feeling stigmatized by the program. This may be explained by the administrative aspect of precariousness as defined by the study; these women have already taken administrative steps to document their low financial status and to gain access to a dedicated health insurance (CMU or AME), which implies that they are well aware of their financial issues. All of them expressed positive views 
regarding the fact that they could benefit from what they see as financial assistance during pregnancy. They all perceived this cash transfer to be helpful.

Finally, the health professionals insisted that they do not believe that the CCT program is the best way to get these women to consult. This discourse concurs with the results of other studies showing that while CCTs can encourage women to consult, it is essential to have the appropriate health facilities in which to receive the patient $(20,21)$. They indicated that dedicated units, taking into account the woman's global situation and with enough staff to call women who did not attend their appointments would be preferable. However, patient navigation during pregnancy has mostly been found effective in low and medium income countries (32). Additionally, our experience suggests that phone calls would not be enough because many women, particularly those whose prenatal follow-up care was inadequate, were really hard to reach for this study. Non-adherent women, very often combining social and economic vulnerability, are not easily accessible. Fieldwork, potentially linked to economic incentives based on the results of this study, would then be preferable to telephone reminders, but this would require even more resources.

\section{Conclusion}

In a country where access to health care is facilitated by a national health insurance system that provides free-of-charge prenatal follow-up, the implementation of a CCT to improve medical follow-up during pregnancy may be seen as ethically questionable, particularly by health professionals. However, the interviews conducted with women who received a cash incentive revealed that they did not feel stigmatized by the CCT, and the women indicated that the money helped them to prepare for the birth of their baby. At the same time, they unanimously maintained that their attitudes towards medical follow-up during pregnancy were not affected by the cash incentive. These data will be verified with the quantitative results of the NAITRE study which is currently being conducted.

\section{Abbreviations}

CCT : Conditional Cash Transfert

\section{Declarations}

The investigators have no conflicts of interest to declare.

\section{*NAITRE study group:}

CHU Besançon : Dr Astrid ECKMAN-LACROIX, Dr Aude BOURTEMBOURG, Dr Claire TOUBIN

CHRU Brest, Pr Philippe MERVIEL, Mme Danièle ADDES, Mme Véronique UGUEN, Mme Cleo TOURBOT, Dr Caroline LELIEVRE, Dr Jacob HANNIGSBERG, Dr Christophe TREMOUILHAC, Dr Anne-Hélène SALIOU, Dr Aurelie DERRIEU, Dr Stephanie AUGET, Dr Anne LEGOURRIEREC, Mme Frédérique FALCHIER 
CHU Lyon - Hôpital Femmes-Mères-Enfants, Pr Muriel DORET, Mme Anne LEROUX, Mme Julie FORTJACQUIER, Mme Marion SERCLERAT, Mme Nathalie LAURENCEAU, Mme Audrey RENOULEAU

CHRU Lille, Pr Damien SUBTIL, Mme Eliane CATTEAU, Pr Philippe DERUELLE

AP-HM Hôpital Nord, Pr Xavier CARCOPINO-TUSOLI, Dr Nathalie LESAVRE, Dr Julie BLANC, Dr Candice RONIN, Dr Laurence PIECHON, Dr Séverine PUPPO, Dr Fanny GRECO, Mme Sandrine PETTAZZONI, Mme Muriel ATHLANI, Mme Amina DESVIGNES, Mme Annie PETITEAU, Mme Amina EL YAAKOUBI, Mme Valérie BECHADERGUE, Mme Valérie VAUGIRARD

AP-HP Bicêtre, Dr Marie-Emmanuelle Neveu, Dr Caroline GEYL, Dr Elodie DEBRAS, Pr Marie-Victoire SENAT, Pr Hervé FERNANDEZ, Dr Claire COLMANT, Dr Marie HOULLIER, Mme Myriam VIRLOUET, Dr Elise THELLIER

AP-HP Robert Debré, Pr Thomas SCHMITZ, Mme Marion MIR, Mme Yasmina BEJAOUI, Mme Hélène LE CORNU, Mme Lauriane NIKEL, Mme Elodie GUSTAVE

CHU Saint-Etienne, Pr Céline CHAULEUR, Dr Amandine STADLER, Dr Ahmad MEHDI, Dr Tiphaine BARJAT, Dr Suzanne LIMA, Dr Thomas CORSINI, Dr Anne GENOD, Dr Charlotte VERMESCH, Dr Cécile FANGET, Dr Marianne PERROT, Mme Manuela MUNOZ, Mme Sylvie PITAVAL, Mme Fanny MAGAND, Mme Françoise BALDI, Mme Stephanie BRET, Mme Anne-Lise VERDIER

CHU Tours, Pr Franck PERROTIN, Dr Christelle DENIS, Dr Carine ARLICOT, Dr Caroline DIGUISTO, Dr Jérôme POTIN, Dr Stéphanie CHRETIEN, Dr Julie PATERNOTTE, Dr Nathalie TRIGNOL, Dr Élisabeth BLIN, Dr Camille MATHIEU, Dr Anne DUBREUIL, Mme Anne VIALLON PELLETIER, Mme Catherine GUERIN, Dr Chloé ARTHUIS

CHU Toulouse, Pr Christophe VAYSSIERES, Pr Olivier PARANT, Dr Marion GROUSSOLLES, Mme Maria DENIS, M Mathieu MORIN

Saint-Etienne Cabinet de SF libérales, Mme Marie-Thérèse BAVOUX, Mme Juliette PELLOUX

CH Tourcoing, Dr Anne-Claire JAMBON, Mme Madeleine SANTRAINE, Mme Veronique LEBUFFE

CH Sambre-Avesnois, Mme Pascale BROUX, Dr Thierry DZUKOU, Dr Magloire GNANSOUNOU, Dr Didier HUBERT, Dr Claire DJAZET, Dr Ludivine DESTOOP, Mme Marine DERUE

CH Saint-Quentin, Dr Pierrick THERET, Mme Dominique DELZENNE, Mme Stéphanie DAUSSINDr Céline BROCHOT, Dr Alice FRAISSINET, Dr Mélanie VANNERUM

CH de Chartres, Dr Cyril FARAGUET, Mme Laurence LANDAIS, Dr Mariana RADU, Mme Anne ROUGET, Dr Sena AL SUDANI 
$\mathrm{CH}$ Jura Sud - Lons-Le Saunier, Dr Bernard GUILLON, Mme Estelle WUCHER, Mme Véronique SELVA, Dr Sandrine REVIRON, Dr Francis SCHWETTERLÉ, Dr Cécile CHASSANDE, Dr Véronique GRANDIN, Dr Eliane KRTOLIZA, Dr Patrick BECHER

CHU BORDEAUX, Pr Loïc SENTILHES, Pr Dominique DALLAY, Dr Marie SARRAU, Dr Clémence HOUSSIN, Dr Claire LECOQ, Dr Elsa LUTRINGER, Dr Denis ROUX, Dr Noémie BERGE, Dr Frédéric COATLEVEN, Dr Clémentine BARBIER

CH Dreux, Dr Claude VIRTOS, Mme Anne HERON, Mme Audrey FARINA-BRACQUART, Mme Marie-Paule CURTET, Mme Evelyne LEFEBURE, Mme Marie-Hélène LE DOUARIN

CH Cambrais, Dr Hassan AL RAYES,

CH Firminy, Dr Émilie MAGNE, Mme Nathalie DESTAMPES

CH SALON, Dr Émilie RICARD, Mme Pascale GHEZZI, Mme Catherine GUILLEN, Mme Fanny ALAZARD, Mme Marie-Thé CAMPANARO, Mme Florence MOJARD, Dr Magalie DAVID-REYNARD, Mme Patricia FUMA, Dr Remy DE MONTGOLFIER, Mme Capucine NEEL

CHU ANGERS, Dr Guillaume LEGENDRE, Pr Philippe GILLARD, Mme Isabelle ANDRE, Mme Sylvie NORDSTROM

CH VALENCIENNES, Dr Brigitte GUIONNET,

AP-HP Louis-Mourier, Pr Olivier PICONE, Pr Laurent MANDELBROT, Dr Catherine CRENN HEBERT, Dr Jeanne SIBIUDE, Dr Chloé DUSSAUX, Mme Karine ACHAINTRE, Mme Anne WAGNER, Mme martine WERVEAKE, Mme Eloïse DE GOUVILLE, Mme George THERESIN, Mme Marie Pierre COUETOUX

CENTRE MUNICIPAL DE SANTÉ Les Pavillons Sous-Bois, Dr Lydia Caillaud,

CH VALENCE, Dr Marie-Pierre FERNANDEZ, Mme Sabrina BOTTET, M Alain ALMODOVAR, Mme Elisa ETIENNE, Mme Véronique GUITERAS, Mme Angélique TORRES, Mme N. ROCHE, Mme Myriam NASSEF, Mme Christine ABEL-FAURE, Mme Marie LOUVET, Mme Carole ETTORI, Mme Karine CHEMIN

CH LA ROCHE SUR YON, Dr Guillaume DUCARME, Dr Valérie BONNENFANT-MEZERAY, Mme Laurence SZEZOT-RENAUDEAU, Mme Marie-Pierre BERTE, Mme Elodie NETIER-HERAULT, Mme Stéphanie MANSON-GALLONE

CH TOULON - Hôpital Sainte Musse, Dr Franck MAUVIEL, Mme Nathalie AGOSTINI , Mme Marine MAZEAUD , Dr Jean-Claude DAUSSET, Mme Isabelle DE MURCIA , Mme Emilie ALLIOT , Mme Anne-Marie BES , Mme Magali BIFERI Magali

AP-HM - La Conception , Dr Hélène HECKENROTH, Dr Sophie MORANGE , Mme Gersende CHIUOT , Dr Audrey GNISCI , Mme Annie ALLEGRE, Mme Laetitia LECQ , Dr Eva BALENBOIS , Dr Claire TOURETTE , Dr 
Aude FIGARELLA, Dr Dio ANDRIAMANJAY

CH DRAGUIGNAN, Dr Pauline VIGNOLES,

$\mathrm{CH}$ AUCH, Mme Catherine CAZELLES, Dr Véronique LEJEUNE SAADA

CH EAUBONNE (S.Veil), Mme Benafsheh KASHANI, Dr Vincent VILLEFRANQUE , Mme Isabelle CHEVALIER , Mme Muriel TERRIERES, Mme Audrey COINTEMENT, Mme Valérie BENHAÏM , Mme Najat LINDOUNE

CH DENAIN, Mme Anne-Sophie MAISONNEUVE, M Frédéric DAUBERCY

CH TARBES, Dr Guilia MENCATTINI,

CH SAUMUR, Dr Vanessa COMBAUD, Dr Isabelle MOYA

Hôp St Joseph - MARSEILLE, M Xavier-Côme DONATO, Dr Raoul DESBRIERE

CH du CHINONAIS, Mme Marie LAFON, Mme Véronique BAUDET

\section{Acknowledgments:}

The authors thank Suzanne Rankin from Dijon-Bourgogne University Hospital for English language editing of the manuscript.

The authors would like to express their gratitude to the women who participated in the NAITRE study, and particularly agreed to participate in the qualitative survey, as well as to the health professionals who took care of the mother and their babies.

\section{Ethics approval and consent to participate, consent for publication}

Ethics approval from CPP EST-I ( $\left.n^{\circ} 2014 / 52\right)$ was first gained on September $28^{\text {th }} 2014$ (N ID RCB : 2014A01319-38).

The participants all agreed to participate in this study after reading an "information note" describing the purpose, method and use of the data (analysis and publication). The consent was verbal as the French Law (Loi Jardé) authorizes it. This was approved by the ethic committee along with the rest of the protocol.

\section{Competing interests}

Authors has no competing interest to declare

\section{Funding}


This study is funded by a call for proposals from the Health Office -France (PREPS). The funding body did not interact in the study.

\section{Authors' contributions}

AGM: substantial contributions to the conception; collect of data, analysis; interpretation of data; drafted the work.

NMB : substantial contributions to the conception; collect of data, analysis; interpretation of data; drafted the work

$\underline{P D}, M M, C V, \underline{A E L}, \underline{E D}:$ Inclusions, revised the work

$\underline{\mathrm{LL}}$ : contribution to collect of data, monitoring, revised the work

$\underline{\mathrm{MB}}$ : conception of the study, substantively revised the work

All authors have read and approved the manuscript

Acknowledgements to the NAITRE study group, patients who agreed to participate while they were young mother, health professional.

Avaibility of data and materials : Data are available by asking to the first author (amarceau@chubesancon.fr). Data available : transcript interviews, analysis table

\section{References}

1. Blondel B, Lelong N, Kermarrec M, Goffinet F, National Coordination Group of the National Perinatal Surveys. Trends in perinatal health in France from 1995 to 2010. Results from the French National Perinatal Surveys. J Gynecol Obstet Biol Reprod (Paris). juin 2012;41(4):e1-15.

2. Brugier $\mathrm{C}$, Morel $\mathrm{O}$, Ricbourg $\mathrm{A}$, Bréchat $\mathrm{PH}$, Gayat $\mathrm{E}$, Barranger $\mathrm{E}$. [Impact of precariousness on quality of prenatal detection: Lariboisière hospital experience in Paris]. J Gynecol Obstet Biol Reprod (Paris). sept 2012;41(5):454-9.

3. Larrañaga I, Santa-Marina L, Molinuevo A, Álvarez-Pedrerol M, Fernández-Somoano A, JimenezZabala $A$, et al. Poor mothers, unhealthy children: the transmission of health inequalities in the INMA study, Spain. Eur J Public Health. 1 juin 2019;29(3):568-74.

4. Glassman A, Duran D, Fleisher L, Singer D, Sturke R, Angeles G, et al. Impact of conditional cash transfers on maternal and newborn health. J Health Popul Nutr. déc 2013;31 (4 Suppl 2):48-66.

5. Azria E, Blondel B, Estellat C, Luton D, Oury J-F, Schmitz T, et al. Association between prenatal care utilization and severe perinatal and maternal morbidities: an analysis within the precare cohort: 632 . Am J Obstet Gynecol [Internet]. janv 2017 
6. Oduenyi C, Ordu V, Okoli U. Assessing the operational effectiveness of a maternal and child health $(\mathrm{MCH})$ conditional cash transfer pilot programme in Nigeria. - Abstract - Europe PMC [Internet]. available on : https://europepmc.org/article/med/31419952

7. Nery JS, Pereira SM, Rasella D, Penna MLF, Aquino R, Rodrigues LC, et al. Effect of the Brazilian Conditional Cash Transfer and Primary Health Care Programs on the New Case Detection Rate of Leprosy. PLoS Negl Trop Dis. 20 nov 2014;8(11):e3357.

8. Silva F de S, Queiroz RC de S, Branco MDRFC, Habenschus MIAT, Scorzafave LG, Saraiva M da CP, et al. [Targeting and coverage of the Bolsa Família program in children from the BRISA Birth Cohorts, Ribeirão Preto (São Paulo State) and São Luís (Maranhão State), Brazil]. Cad Saude Publica. 4 juill 2019;35(6):e00159718.

9. Gertler P. Do Conditional Cash Transfers Improve Child Health? Evidence from PROGRESA's Control Randomized Experiment. Am Econ Rev. avr 2004;94(2):336-41.

10. Fernald LCH, Gertler PJ, Neufeld LM. The Importance of Cash in Conditional Cash Transfer Programs for Child Health, Growth and Development: Lancet. 8 mars 2008;371(9615):828-37.

11. Noordraven EL, Wierdsma Al, Blanken P, Bloemendaal AFT, Staring ABP, Mulder CL. Financial incentives for improving adherence to maintenance treatment in patients with psychotic disorders (Money for Medication): a multicentre, open-label, randomised controlled trial. Lancet Psychiatry. 2017;4(3):199-207.

12. Vaz-Carneiro A, Costa J. [Analysis of the Cochrane Review: Incentives for Smoking Cessation. Cochrane Database Syst Rev. 2015;5:CD004307]. Acta Med Port. janv 2016;29(1):12-4.

13. Berlin N, Goldzahl L, Jusot F, Berlin I. Protocol for study of financial incentives for smoking cessation in pregnancy (FISCP): randomised, multicentre study. BMJ Open. 1 juill 2016;6(7):e011669.

14. Triyana $M$, Shankar AH. The effects of a household conditional cash transfer programme on coverage and quality of antenatal care: a secondary analysis of Indonesia's pilot programme. BMJ Open. oct 2017;7(10):e014348-e014348.

15. Till SR, Everetts D, Haas DM. Incentives for increasing prenatal care use by women in order to improve maternal and neonatal outcomes. Cochrane Database Syst Rev. 15 déc 2015; (12):CD009916.

16. Rawlings LB. Evaluating the Impact of Conditional Cash Transfer Programs. World Bank Res Obs. 1 mars 2005;20(1):29-55.

17. Bardou M, Crépon B, Bertaux A-C, Godard-Marceaux A, Eckman-Lacroix A, Thellier E, et al. NAITRE study on the impact of conditional cash transfer on poor pregnancy outcomes in underprivileged women: protocol for a nationwide pragmatic cluster-randomised superiority clinical trial in France. BMJ Open. 1 oct 2017;7(10):e017321.

18. Tonguet-Papucci A, Houngbe F, Lompo P, Yameogo WME, Huneau J-F, Ait Aissa M, et al. Beneficiaries' perceptions and reported use of unconditional cash transfers intended to prevent acute malnutrition in children in poor rural communities in Burkina Faso: qualitative results from the MAM'Out 
randomized controlled trial. BMC Public Health [Internet]. available on https://www.ncbi.nlm.nih.gov/pmc/articles/PMC5450256/

19. Hjelm L, Handa S, de Hoop J, Palermo T, Zambia CGP and MCP Evaluation Teams. Poverty and perceived stress: Evidence from two unconditional cash transfer programs in Zambia. Soc Sci Med 1982. 2017;177:110-7.

20. Godard A, [Women's work in Guinea], L'harmattan.

21. Maruani, M., [Labour and Gender in the world, the state of knowledge] -Editions La Découverte

22. Sidney K, Tolhurst R, Jehan K, Diwan V, De Costa A. 'The money is important but all women anyway go to hospital for childbirth nowadays' - a qualitative exploration of why women participate in a conditional cash transfer program to promote institutional deliveries in Madhya Pradesh, India. BMC Pregnancy Childbirth. 4 mars 2016;16(1):47.

23. De Koninck M. Le discours des femmes sur leur santé, un savoir essentiel pour l'intervention. Rech Féministes. 12 avr 2005;10(1):97-112.

24. Marie CFS, Querrioux I, Baumann C, Patrizio PD. Difficultés des médecins généralistes dans la prise en charge de leurs patients précaires. Sante Publique (Bucur). 31 déc 2015;Vol. 27(5):679-90.

25. Bédécarrats F, Guérin I, Roubaud F. All that Glitters is not Gold. The Political Economy of Randomized Evaluations in Development. Dev Change. 2019;50(3):735-62.

26. Doligez F. L'Économie comportementale en question, Jean-Michel Servet, éditions Charles Léopold Mayer, 2018, 208 pages. RECMA. 9 oct 2018;ํํ350(4):114-6.

27. Kvangraven IH. Impoverished economics? A critical assessment of the new gold standard. World Dev. 1 mars 2020;127:104813.

28. Fries, J.F., Krishnan, E. Equipoise, design bias, and randomized controlled trials: the elusive ethics of new drug development. Arthritis Res Ther 6, R250 (2004).

29. Kyomuhendo GB. Indignity in Cash Transfers: The Senior Citizen's Grant in Uganda. Int J Soc Qual. 1 déc 2016;6(2):71-88.

30. Gupta A, Fledderjohann J, Reddy H, Raman VR, Stuckler D, Vellakkal S. Barriers and prospects of India's conditional cash transfer program to promote institutional delivery care: a qualitative analysis of the supply-side perspectives. BMC Health Serv Res. 25 janv 2018;18(1):40.

31. Vellakkal S, Reddy H, Gupta A, Chandran A, Fledderjohann J, Stuckler D. A qualitative study of factors impacting accessing of institutional delivery care in the context of India's cash incentive program. Soc Sci Med. 1 avr 2017;178:55-65.

32. Austad K, Juarez M, Shryer H, Moratoya C, Rohloff P. Obstetric care navigation: results of a quality improvement project to provide accompaniment to women for facility-based maternity care in rural Guatemala. BMJ Qual Saf. 2 nov 2019;

\section{Tables}

Table 1 : Inclusion/centre and control/intervention

Page 18/19 


\begin{tabular}{|lccc|c|}
\hline & intervention & control & total \\
\hline Besançon & 3 & 3 & 6 \\
Paris & 4 & 6 & 10 \\
Lille & 5 & 1 & 6 \\
Toulouse & 2 & & 2 \\
Dreux & & 2 & 2 \\
\hline Total & 14 & 12 & 26 \\
\hline
\end{tabular}

Table 2 : Characteristics of the women

\begin{tabular}{|lr|}
\hline & $\mathrm{N}$ \\
\hline average age & 31 \\
median age & 30 \\
\hline primiparous & 6 \\
multiparous with at least 1 child at home & 11 \\
\hline Marital status & \\
lives alone & 2 \\
lives with a spouse & 24 \\
\hline Precarious housing & \\
yes & 4 \\
no & 22 \\
\hline Professional situation & \\
Craftsmen, sales persons, business owners & 2 \\
Students (including internship) & 2 \\
Employees & 2 \\
Unemployed (unemployment, housewife,...) & 20 \\
\hline
\end{tabular}

\section{Supplementary Files}

This is a list of supplementary files associated with this preprint. Click to download.

- NAITREPROFESSIONNELGrilleEntretienV2.pdf

- NAITREISSMCOREQChecklist2mars2020.pdf

- NAITREgrilleEntretien.pdf 